\title{
Estrategias para la inclusión de estudiantes indígenas en la Universidad Nacional de Salta (UNSa), Argentina
}

Strategies for the Inclusion of Indigenous Students in the National University of Salta (UNSa), Argentina

\author{
Volumen 22, Número 1 \\ Enero - Abril \\ pp. 1-35
}

Nuria Macarena Rodríguez

Citar este documento según modelo APA

Rodríguez, Nuria Macarena. (2022). Estrategias para la inclusión de estudiantes indígenas en la Universidad Nacional de Salta (UNSa), Argentina. Revista Actualidades Investigativas en Educación, 22(1), 1-35. Doi. https://doi.org/10.15517/aie.v22i1.49069 


\title{
Estrategias para la inclusión de estudiantes indígenas en la Universidad Nacional de Salta (UNSa), Argentina
}

\author{
Strategies for the Inclusion of Indigenous Students in the National University of Salta (UNSa),
} Argentina

\section{Nuria Macarena Rodríguez ${ }^{1}$}

\begin{abstract}
Resumen: Este artículo analiza las estrategias de inclusión de estudiantes indígenas en la Universidad Nacional de Salta (Salta, Argentina) a partir de una política educativa institucional; a saber, el proyecto de Tutorías con Estudiantes de Pueblos Originarios. El estudio contempla las estrategias de permanencia y retención en dicho proyecto. Se decide abordar esta política educativa porque se le considera una experiencia que contribuye a cuestionar el Modelo Civilizatorio Moderno Colonial y avanzar hacia una inclusión intercultural en las universidades nacionales argentinas. La investigación se realizó desde una lógica cualitativa y consistió en un estudio de caso con enfoque etnográfico. La información que se analiza se obtuvo mediante observaciones participantes y entrevistas orientadas a la narrativa autobiográfica. El trabajo de campo se realizó durante el período comprendido entre los años 2016 y 2019. La investigación realizada permitió identificar tres ejes centrales en las estrategias de inclusión de estudiantes indígenas en la Universidad Nacional de Salta: la reivindicación de la identidad indígena como estrategia de permanencia; los aspectos formativos como estrategia de retención; y los lazos afectivos como estrategias de retención y permanencia. El análisis de estos tres ejes, así como de las expectativas a futuro de quienes conforman los espacios de tutorías permiten reconocer cómo estos últimos posibilitan tejidos de contención que se constituyen en experiencias de inclusión intercultural. Sin embargo, esta característica no puede, todavía, generalizarse a toda la Universidad, ya que no se evidencian, por fuera del Proyecto analizado, esfuerzos por incluir al estudiantado indígena en la UNSa en términos interculturales.
\end{abstract}

Palabras clave: universidad, educación inclusiva, educación intercultural, población indígena.

Abstract: This article analyzes the strategies for the inclusion of indigenous students in the National University of Salta (Salta, Argentina) based on an institutional educational policy aimed at this group of students: The Tutoring Project with Students from Indigenous Peoples. The analysis considers the strategies of permanence and retention. It is decided to analyze this educational policy because it is considered as an experience that contributes to questioning the Modern Colonial Civilization Model and moving towards intercultural inclusion in Argentine national universities. The research was carried out from a qualitative logic, it consisted of a case study with an ethnographic approach. The information that is analyzed in this article was obtained through participant observations and interviews oriented to the autobiographical narrative. The field work was carried out during the period between 2016 and 2019. The information generated allowed the identification of three central axes in the strategies for the inclusion of indigenous students at the National University of Salta: the claim of indigenous identity as a strategy for permanence, training aspects as retention strategy and affective ties as retention and permanence strategies. The analysis of these three axes, as well as the future expectations of those who make up the tutoring spaces, allow us to recognize how the tutoring spaces generate tissues of containment that constitute experiences of intercultural inclusion. However, this characteristic cannot yet be generalized to the entire university.

Key words: university, inclusive education, intercultural education, indigenous people.

${ }^{1}$ Investigadora del Instituto de Investigaciones en Ciencias Sociales y Humanidades, CONICET-Universidad Nacional de Salta, Salta, Argentina. Doctora en Humanidades, Área Educación, por la Universidad Nacional de Tucumán, Argentina. ORCID: https://orcid.org/0000-0003-3692-294X

Dirección electrónica: nuria.macarena.rodrgiguez@gmail.com

Artículo recibido: 30 de junio, 2021

Enviado a corrección: 27 de setiembre, 2021

Aprobado: 25 de octubre, 2021

Los contenidos de este artículo están bajo una licencia Creative Commons 


\section{Introducción}

Las universidades argentinas son consecuencia de la colonización y su historia debe "comprenderse en el mismo contexto de evolución de las universidades occidentales" (Buchbinder, 2006, p. 2). En tal sentido, quizá, la universidad sea una de las más fuertes instituciones coloniales del saber occidental. La investigación en la que se sustenta este trabajo $^{2}$, parte de una crítica al Modelo Civilizatorio Moderno Colonial (MCMC), que legitima los conocimientos occidentales, impuestos como universales, en detrimento de aquellos que no responden a los parámetros eurocéntricos y, por tanto, son negados.

Históricamente, la educación formal fue un bastión del MCMC, desde el cual se intentó reproducir sus valores como universales. Sus instituciones, en general, y las universidades, en particular, investidas de inclusivas y accesibles, en ocasiones, son excluyentes para muchas personas. Sin embargo, es la misma educación empleada para la (re)producción del modelo la que puede ser una herramienta que permita producir cambios, para emancipar, y en tal sentido, constituirse en una "práctica de la libertad" (Freire, 1987, p. 74). Es decir, que aun siendo la educación que conocemos una consecuencia de la colonialidad y una reproductora de esta, es posible encontrar en ella espacios para permear, agrietar y tensionar dicho modelo y poner en cuestión sus principios desde sus propias instituciones, a partir de reconfiguraciones de los sentidos asociados a ellas.

Los procesos de visibilización de luchas sociales, movimientos anticapitalistas, campesinos e indígenas, las disidencias sexuales, los feminismos, entre otros se erigen como intersticios que anuncian una crisis de legitimidad del MCMC. Esta situación muestra la posibilidad de otras formas de conocer, de estar y de ser en el mundo, diferentes de las hegemónicas, y pone en cuestión los relatos modernos. Nos encontramos, entonces, ante procesos que resquebrajan los fuertes cimientos del MCMC en sus tres facetas: el capitalismo, la colonialidad y el patriarcado. Las formas lineales de regulación social y la anulación de la imaginación como instancia de producción de formas de ser y de saber debilitan y permean el MCMC (González, 2020).

Las universidades no son la excepción, en ellas también se encuentran posibles intersticios que habilitan cambios. La investigación de estos y el estudio específico de las

\footnotetext{
2 El presente artículo tiene su base en la Tesis Doctoral de su autora, en la que se analizaron las estrategias para la inclusión de Estudiantes Indígenas en la Universidad Nacional de Salta (UNSa) a partir de la experiencia del Proyecto de Tutorías con Estudiantes de Pueblos Originarios (ProTconPO) (2016-2019). Este último constituye una política educativa institucional dirigida específicamente a estudiantes indígenas, que se aprobó en dicha Universidad en 2010.
} 
experiencias que los generan constituyen herramientas que posibilitan poner en cuestión el MCMC y pensar en instituciones cada vez más inclusivas. Por ello, la investigación se centra en el estudio de una política educativa institucional en la Universidad Nacional de Salta (UNSa), orientada a la atención y retención de estudiantes indígenas: el Proyecto de Tutorías con Estudiantes de Pueblos Originarios (ProTconPO). Este artículo analiza la experiencia del estudiantado en la universidad y su participación en el ProTconPO.

Siguiendo la clasificación que realiza Mato (2015), la UNSa es una Universidad Convencional, ya que no ha sido pensada -desde sus orígenes- para atender la diversidad cultural ni para dar respuesta a demandas de los pueblos indígenas. Se encuentra ubicada en la provincia con mayor diversidad de Pueblos Indígenas de Argentina ${ }^{3}$ y, a pesar de ello, no se reconoció institucionalmente la presencia de estudiantes indígenas sino hasta el año 2008. El ProTconPO constituye la primera política de la universidad dirigida a estos grupos y se le considera como una experiencia que puede posibilitar la apertura de nuevos horizontes institucionales en la UNSa. En este punto es importante anticipar que quienes participan en el ProTconPO han conformado lo que decidieron denominar Comunidad de Estudiantes Universitarios de Pueblos Originarios (CEUPO).

Así pues, el objeto de estudio de la investigación son las estrategias de inclusión de estudiantes indígenas en la UNSa a partir de la experiencia del ProTconPO (2016-2019). Se optó (con fines analíticos) por considerar dos modalidades: estrategias de retención y estrategias de permanencia. Las primeras aluden a las políticas elaboradas institucionalmente para intentar favorecer la continuidad de la población estudiantil indígena en la Universidad. Las segundas dan cuenta de aquellas que pone en práctica el estudiantado indígena para continuar sus estudios universitarios.

El objetivo de la investigación consistió en comprender las estrategias de inclusión de estudiantes indígenas que se desarrollan en la UNSa, a partir del análisis de las experiencias del ProTconPO y el CEUPO (2016-2019). El proceso investigativo permitió identificar tres ejes centrales en las estrategias de retención y permanencia desplegados en la UNSa, para la inclusión de estudiantes indígenas, a partir del ProTconPO, los cuales se retoman en este

\footnotetext{
3 Salta es una provincia ubicada al norte de Argentina, limita con seis provincias (Jujuy, Catamarca, Tucumán, Santiago del Estero, Chaco y Formosa) y tres países (Paraguay, Bolivia y Chile). En ella, hay 79.204 personas que se reconocen como indígenas o descendientes, lo que representa el 6,5\% de la población total, muy por encima del 2,4\% a nivel nacional (INDEC, 2010). Además, esta es la provincia que presenta la mayor diversidad de pueblos originarios: Kolla, Wichí, Guaraní, Ava Guaraní, Weenhayek, Chané, Chorote, Qom (Toba), Chulupí, Tapiete, Diaguita-calchaquí, Tastil, logys, Atacama y Lule (Rodríguez y Sulca, 2020).
} 
artículo. Estos son: los lazos afectivos, la reivindicación de la identidad indígena del estudiantado y los aspectos formativos.

Es importante mencionar que se consideró importante analizar, a partir de los ejes mencionados, aquello que quienes componen el CEUPO y el ProTconPO reconocen como fortalezas y debilidades de estos espacios. Finalmente, y con base en este desarrollo, se abordarán las expectativas y perspectivas a futuro respecto al CEUPO y el ProTconPO.

\section{Referente Teórico}

\subsection{Horizontes y utopías: inclusión en términos interculturales}

Existen múltiples definiciones del término inclusión, su uso es profuso y muchas veces confuso, por lo que resulta importante clarificar la acepción con la que se emplea en nuestra investigación. Para hablar de inclusión es necesario hacer referencia a la exclusión porque la primera es consecuencia del reconocimiento de la existencia de la segunda y de la importancia de intervenir para atender a quienes resultan excluidos y excluidas (Wigdorovitz de Camilloni, 2008). Entonces, ¿quiénes son excluidos? Poblaciones de zonas rurales remotas, poblaciones indígenas, pobres, minorías lingüísticas y religiosas, personas con discapacidad, cada persona que es diferenciada de los demás y -por tal razón- pesa sobre ella un estigma social (Wigdorovitz de Camilloni, 2008). En síntesis, son quienes se alejan de los parámetros del MCMC y, por consiguiente, se invisibilizan, se niegan y se descartan.

Los sentidos de inclusión vinculados a las posibilidades de escolarización forman parte de las diferentes visiones respecto de los motivos y los logros que se persiguen a través de la educación formal. Esto es más significativo si se piensa en la educación superior, que no es obligatoria. Además, implica reconocer que la inclusión y la exclusión son categorías analíticas que, en ciertas ocasiones, no llegan a dar cuenta de la complejidad de las trayectorias socioescolares reales de los sujetos, quienes se apropian de los espacios académicos de formas particulares, y con base en condiciones de existencia inequitativas, desiguales y diversas (Rodríguez y Ossola, 2019).

En el caso particular de los pueblos indígenas, esto se relaciona, además, con las tensiones entre las expectativas de inclusión y las de distinción (Novaro y Hecht, 2017), las cuales ponen en cuestión el MCMC. Así pues, exigen una inclusión en su diversidad, en su particularidad, con su bagaje cultural, lingüístico y conocimientos previos y no a condición de abandonar sus culturas. Esta forma de concebir la inclusión, que no implica la superioridad de 
un grupo -inclusor- sobre otro -a ser incluido-, sino un diálogo entre culturas es la que hemos decidido llamar inclusión en términos interculturales.

Tal modo de entender la inclusión se sustenta en la idea de diálogo, característica central en el concepto de interculturalidad comprendida como encuentro de autopoiesis de las culturas, de convivencia y comunicación entre ellas (Tintaya Condorí, 2003). Así, la interculturalidad -en su concepción crítica- requiere la transformación de las estructuras, instituciones y relaciones sociales, además, precisa de la construcción de condiciones de estar, ser, pensar, conocer, aprender, sentir y vivir otras (Walsh, 2010).

En este sentido, dada su naturaleza universalista, moderna y colonial, las universidades convencionales argentinas distan mucho de ser inclusivas en términos interculturales. Esto no se relaciona con las estadísticas de ingreso, sino con las posibilidades de diálogo intercultural que no logran generar debido a seguir respondiendo lógicas occidentalistas. No obstante, existen experiencias que permiten vislumbrar nuevos horizontes que, si bien pueden parecer utópicos, se constituyen en intersticios para poner en cuestión al MCMC e imaginar otras formas de inclusión en estas instituciones. La idea de diálogo permite pensar, aunque sea utópicamente, en una inclusión que no sea en un solo sentido: desde quien incluye hacia quien "debe ser" incluirse; sino en varios sentidos que impliquen incluir e incluirnos. Además, es necesario contemplar la posibilidad de que las personas "excluidas" pueden no querer serlo, en los términos que externamente se consideran los adecuados. Por ello, se torna importante poder pensar una inclusión que signifique un diálogo entre culturas o sectores sociales en lugar de una inclusión acrítica, que supone la superioridad de un grupo -inclusor- sobre otro a ser incluido-.

\subsection{Estrategias de retención en universidades argentinas}

Si bien a nivel estatal no se ha avanzado significativamente respecto a las demandas indígenas de educación superior (Rosso, 2019), la autonomía de la que gozan las universidades nacionales argentinas posibilita la implementación de políticas institucionales para la atención de las diferentes problemáticas de estos estudiantes. Actualmente, son ocho las universidades públicas argentinas que cuentan con políticas de esta índole.

De este modo, se encuentra, en la Universidad Nacional de Cuyo (UNCuyo), un Programa de becas de ayuda económica, comedor y alojamiento para estudiantes indígenas (2003); en la Universidad Nacional de Misiones (UNaM), el Programa Especial de Promoción y Apoyo a Estudiantes guaraníes que cursan carreras en la Facultad de Humanidades y 
Ciencias sociales, e Institutos de Educación Superior: Oñopytyvó Va'eukéry Oñemboeboeápy (2009); en la Universidad Nacional del Nordeste (UNNE), el Programa de Pueblos Indígenas (2010); en la Universidad Nacional de San Juan (UNSJ), el Programa Universitario de Asuntos Indígenas (2012); en la Universidad Nacional de Rosario (UNR), el Programa intercultural para estudiantes de Pueblos Originarios (2013); en la Universidad Nacional del Litoral (UNL), el Programa Pueblos Originarios (2013), y en la UNSa, el Proyecto de Tutorías con Estudiantes de Pueblos Originarios (Guaymás, 2018), caso analizado en esta investigación. A los siete proyectos que menciona Guaymás (2018), se agrega, recientemente, en la Universidad Nacional de San Luis (UNSL), el Programa de Pueblos Indígenas (2020). Son estas estrategias las que se denominan de retención, ya que implican esfuerzos institucionales por favorecer la continuidad del estudiantado.

Hanne (2014) señala que existe interés de algunas universidades por incluir en sus agendas el tema indígena desarrollando un genuino compromiso para los y las estudiantes indígenas mediante el diseño e implementación de políticas y estrategias que propician espacios inclusivos, en donde sus derechos puedan ser materializados en acciones concretas. Estos proyectos propician un acompañamiento académico e intentan generar condiciones de respeto a su identidad en el ámbito universitario, lo cual se considera necesario para disminuir las posibilidades de abandono y potenciar los aprendizajes (Rosso, et al., 2016).

Como motivaciones de la decisión política por aprobar estos proyectos se pueden mencionar elementos de las coyunturas provinciales, experiencias en extensión e investigación respecto a la temática desarrollados por equipos de las universidades, y también el antecedente de que otras universidades de América Latina habían implementado proyectos de inclusión de jóvenes indígenas (Rosso et al., 2016).

En relación con esto, Ossola (2013) remarca que las Iniciativas de Base Étnica (IBE) en universidades nacionales forman parte de un conjunto de medidas que expresan tensiones, pujas y reacomodaciones sociales, políticas y pedagógicas más amplias (Ossola, 2013). La noción de IBE refiere a las políticas y programas que buscan atender las necesidades y demandas de estudiantes indígenas en las instituciones de educación superior convencionales (Ossola, 2013).

Hanne (2018) plantea que las dificultades económicas son el principal obstáculo en el acceso a la universidad de estudiantes indígenas. Así, por ejemplo, el Programa Pueblos Indígenas (PPI) otorga, desde 2011, becas para apoyar el ingreso de jóvenes indígenas a las carreras de grado de la UNNE (Luján y Torres, 2014). En otras universidades -como es el 
caso en estudio- no se otorga ninguna ayuda económica específica, pero se procura orientar y asesorar a sus integrantes para la obtención de becas que otorga la universidad (de ayuda económica, de fotocopias, de comedor, etc.), de becas nacionales y provinciales destinadas a estudiantes universitarios en general.

Como aspectos facilitadores de la permanencia, Hanne (2018), desde la perspectiva de estudiantes indígenas, identifica dos principales: características personales (referidas al propio esfuerzo) -que se analizan en este trabajo como estrategias de permanencia- y la presencia de otros sujetos significativos. Con estos últimos se refiere a personas cuyo papel fue importante para facilitar la permanencia de este grupo de estudiantes en la universidad. Al respecto, resulta importante mencionar que entre esos "otros significativos", algunos y algunas estudiantes indígenas de la UNSa mencionan a sus pares del ProTconPO.

Otro de los aspectos que influyen en la permanencia y egreso son las cuestiones académicas, con las cuales se hace referencia a los aspectos relacionados con lo curricular, con los contenidos que se aprenden en las universidades y el modo en que estos pueden ser aprendidos por el estudiantado indígena. Para su atención, existen no solo las tutorías específicas para este sector, sino otros programas tutoriales destinados al estudiantado en general, ya que algunas problemáticas de permanencia y egreso no afectan solo a estudiantes indígenas.

\subsection{Tutorías Universitarias}

Resulta pertinente esclarecer a qué se hace referencia con tutorías. Existen variadas acepciones del término, así como modalidades. El presente trabajo aborda un caso de tutoría universitaria, la que puede definirse como un acompañamiento, orientación y apoyo al alumnado en su proceso de personalización de los aprendizajes y desarrollo de competencias a nivel personal y profesional, a lo largo de su trayectoria, con el horizonte dinámico del proyecto de vida, un proyecto personal y profesional (Lobato Fraile e Ilvento, 2013). Con acompañamiento, se alude a un espacio de encuentro que "tiene carácter permanente de ensayo y puesta en práctica, para pensar con y a otros" (Coronado y Gómez Boulin, 2015, p. 112). Con esto se quiere señalar que no se conciben las tutorías universitarias como cerradas ni acabadas, sino que se construyen y reconstruyen como espacios interactivos y en los mismos vínculos interpersonales.

Es importante tener en cuenta dos aspectos de las tutorías con las que se trabaja: por un lado, que son entre pares, es decir, que tanto tutores y tutoras como tutelados y tuteladas 
son estudiantes de la misma universidad, lo que posibilita rotación en los roles, así como cierta simetría en las relaciones; por otro lado, que la participación es voluntaria: "como toda ayuda, se ofrece, pero no se impone: uno de los principales retos consiste en implicar al alumnado" (Coronado y Gómez Boulin, 2015, p. 118).

La figura de tutores y tutoras pares es valiosa para la inclusión de estudiantes indígenas "ya que se considera fundamental su experiencia en el recorrido universitario para brindar un acompañamiento apropiado en cuestiones académicas, institucionales y motivacionales" (Soto et al., 2020, p. 8). Del mismo modo, se prioriza que estos roles sean desempeñados por estudiantes indígenas, ya que "el tutor indígena posee esta doble "fortaleza", la experiencia en lo académico, por un lado, y la identidad cultural, por el otro" (Soto et al., 2020, p. 9).

En algunas IBE cobra importancia la participación de los referentes indígenas, aunque no es el caso del ProTconPO. Esta participación resulta fundamental si se entiende que la interculturalidad se da a través de la participación indígena (Rosso et al., 2016). Otras de estas iniciativas, entre las que se encuentra el ProTconPO, intentan alentar el desarrollo de proyectos de extensión, en función de las demandas de las comunidades y organizaciones de pueblos indígenas de la región, estos proyectos suelen contar con la participación de estudiantes indígenas, lo cual se constituye en una de las estrategias de permanencia. Asimismo, se busca promover y consolidar equipos de investigación sobre la temática indígena fomentando investigaciones intra e interinstitucionales sobre educación, lenguas, salud, derechos, poblaciones indígenas, entre otros (Rosso et al., 2016).

Si bien es necesario que el Estado asuma una política inclusiva de nivel superior para garantizar el ingreso, retención y graduación de estudiantes indígenas nos interesa reconocer las experiencias que se desarrollan en diferentes universidades nacionales, como espacios desde los cuales se pueden iniciar cambios y cuestionar la lógica universalista y colonial. El valor de estos espacios cobra mayor claridad si se piensan en relación con la raigambre colonial que caracteriza a estas instituciones. Así pues, nos permiten advertir nuevas formas de inclusión, superadoras de aquella concepción unidireccional a la que se refirió en páginas anteriores y más cercanas a la interculturalidad anhelada.

\subsection{Estrategias para la permanencia: estudiantes indígenas en las universidades.}

Como se anticipó, para una perspectiva más acabada de los procesos de inclusión de estudiantes indígenas en universidades convencionales, se complementa el análisis de las 
políticas institucionales con la experiencia de las personas protagonistas de estos proyectos: estudiantes universitarios indígenas. Tales jóvenes, en estas instituciones, experimentan su “inclusión" marcada por tensiones:

el apoyo familiar junto a la desterritorialización; la ayuda de los pares no indígenas de la mano con actitudes que denotan prejuicios y desconocimiento sobre los indígenas; el apoyo de la universidad a través de becas y tutorías en paralelo al muro con el que chocan al experimentar las diferencias entre el nivel medio y el universitario. (Luján, Soto y Rosso, 2018, p. 63)

Carli (2012) sostiene que, para permanecer en una institución de nivel superior, el estudiantado debe desplegar ciertas estrategias mediante las cuales adquieren su condición de estudiantes universitarios, para sortear dificultades hasta culminar o avanzar en el plan de estudios de su carrera. En cuanto a estudiantes indígenas, en el marco de las IBE, desarrollan sus propias estrategias para permanecer en estas instituciones.

Un aspecto importante son los sentidos de la profesionalización de los jóvenes indígenas. Al respecto, el debate pivotea entre dos posiciones contrapuestas: la que sostiene que el ingreso, permanencia y egreso de estudiantes indígenas en universidades convencionales conduce a la pérdida de su identidad indígena, y otra que indica que, como resultado de su trayectoria formativa, los jóvenes indígenas profesionales contribuirán al empoderamiento de sus comunidades (Ossola, 2013). Muchas veces estos debates giran en torno a la idea de "retorno" a las comunidades. Al respecto, Czarny, Ossola y Paladino (2018) señalan que el "retorno" no siempre se da por regresar materialmente a sus comunidades, sino que puede expresarse en la vinculación con la comunidad que no se interrumpe por la distancia física y permite que muchos jóvenes se sientan comprometidos con sus comunidades de procedencia. Permanecer en la universidad adquiere significados diversos para estudiantes indígenas, entre los que contribuir a su comunidad es uno de los principales (Artieda et al., Rosso, Luján y Zamora, 2017). Como sostiene Santana Colin (2018), para el caso de las universidades:

Estos tránsitos escolares pueden convertirse también en una trinchera de resistencia donde los grupos indígenas que se encuentran en posición de subordinación y que han vivido históricamente discriminados, utilizan los conocimientos adquiridos en la universidad para sus propios fines, tanto personales como comunitarios. (p. 108) 
No se puede dejar de mencionar como factor influyente, al menos en la permanencia, y quizá en el egreso- de estudiantes indígenas, la apuesta ético-política por hacer visibles sus identidades indígenas en las universidades. Este aspecto cobra importancia central por cuanto surge como iniciativa propia: "los estudiantes están proponiendo acciones y asumiendo posicionamientos en una búsqueda por hacerse visibles como actores activos ante los demás miembros de la institución" (Soto et al., 2020, p.12). El hecho de que haya indígenas con posibilidad de desempeñarse como tutores por ser estudiantes avanzados es reconocido como un avance, porque es una forma de visibilizar la presencia indígena en la universidad, desde otro posicionamiento, dado que han demostrado poder avanzar en la carrera (Soto et al., 2020).

Luján et al. (2018) identifican como otro aspecto importante, en el desarrollo de estrategias de permanencia, a la conformación de grupos de pares no indígenas. La interacción constituye un aspecto positivo en el proceso de crear nuevos vínculos y se convierte en una condición indispensable para la permanencia en la carrera. Asimismo, este aspecto puede responder a cuestiones académicas, los grupos de estudio son espacios valorados por estudiantes universitarios para sortear dificultades de este tipo (Carli, 2012).

Otra cuestión importante dentro de las estrategias que desarrollan estudiantes indígenas para su permanencia es la participación en proyectos de extensión como forma de mantener el vínculo con sus comunidades. Estos espacios son valorados por ellos en tanto pueden poner en diálogo los conocimientos que tienen por pertenecer a dos comunidades de práctica: la indígena y la universitaria (Ossola, 2018).

En relación con esto, es relevante mencionar que, durante el proceso de permanencia, habitar la universidad adquiere sentidos que exceden el éxito académico, como establecer relaciones interétnicas y crear redes útiles no solo para ellos mismos, sino para futuros y futuras estudiantes indígenas en la universidad, a partir de lo cual se aporta a su rol de "pioneros universitarios [sic]" (Soto et al., 2020). Las estrategias son comunitarias, no responden al objetivo de permanecer individualmente, sino de ir forjando espacios que faciliten las trayectorias a cada estudiante indígena que acceda a la universidad: "el 'ser universitarios', para estos sujetos, adquiere una significación ligada a una idea de superación de sí mismos como comunidad" (Luján et al., 2018). 


\section{Metodología}

\subsection{Enfoque}

Este artículo se inscribe en una lógica cualitativa de investigación porque busca comprender la realidad en estudio a partir de las percepciones de quienes la conforman. Es decir, se conceptualiza a partir de los comportamientos, actitudes, conocimientos y valores de los sujetos que participan en el estudio (Bonilla y Rodríguez, 1997), en interacción con las significaciones de la investigadora (Yuni y Urbano, 2016). Con esto se hace referencia a dos cuestiones centrales de la perspectiva metodológica en la que se sustenta esta investigación. Por un lado, la centralidad otorgada a la experiencia propia de los y las protagonistas -en este caso, participantes de la política institucional en estudio- $y$, por otro, la renuncia a la pretensión de objetividad, en tanto la realidad objetiva es imposible de ser capturada. Cada investigador o investigadora habla desde una comunidad interpretativa particular que le es propia y que configura los componentes culturales y genéricos del acto de investigación (Denzin y Lincoln, 2005). Esto no quiere decir que el trabajo consista en nuestra interpretación subjetiva del caso en estudio, sino que se tiene conciencia de que el análisis realizado y las conclusiones a las que se arriban son producto del diseño elaborado, los caminos elegidos y las decisiones tomadas en el proceso de investigación.

La indagación se realizó a través de un estudio de caso, lo cual supone un análisis de lo particular y lo único. En tal sentido, se presta atención a lo que puede ser estudiado a partir de un caso singular, en términos de Stake (1994), lo que puede ser aprendido a partir de un "ejemplo en acción". Así pues, se consideró que este tipo de estudio resulta pertinente para esta investigación, ya que no tiene pretensiones de realizar generalizaciones, sino de obtener conclusiones situadas.

De los diversos tipos, se realizó un estudio de caso único, ya que el objetivo fue analizar la política educativa institucional específica para pueblos indígenas en la UNSa. Por lo tanto, en esta investigación el caso es el Proyecto de Tutorías con Estudiantes de Pueblos Originarios que se desarrolla en la institución desde el año 2010. La selección se realizó con base en tres criterios principales. Por un lado, y basándonos en los aportes de Stake (1995), se buscó seleccionar un caso que ofreciera mejores y mayores oportunidades de aprendizaje con respecto a la temática general. Por otra parte, se consideró importante la posibilidad de acceso a la información. Por último, pero muy importante, se debe mencionar que la selección responde a un interés personal y un compromiso político con el estudiantado indígena universitario. 
Por otro lado, es pertinente señalar que de la triple significación de la etnografía que presenta Guber (2011), este estudio recuperó aportes en su acepción de enfoque, que constituye "una concepción y práctica de conocimiento que busca comprender los fenómenos sociales desde la perspectiva de sus miembros (entendidos como ‘actores', 'agentes' o ‘sujetos sociales')" (Guber, 2011, p. 16). La especificidad de este enfoque se corresponde con un elemento clave de las ciencias sociales: la descripción. Esta última nunca es neutral ni aséptica, sino que se encuentra siempre apoyada en las lentes del investigador. Así, un cientista social debe reconocer, al menos, tres niveles de comprensión: el "qué" o "reporte", referente a lo que se informa que ha ocurrido; el "porqué" o "explicación", que alude a sus causas; y el "cómo es para ellos" o "descripción", que responde a lo que ocurrió desde la perspectiva de sus protagonistas.

\subsection{Unidades de análisis}

Las unidades de análisis de esta investigación fueron estudiantes que participaban en actividades del ProTconPO y CEUPO, en diversos roles, durante el período de trabajo de campo (2016-2019). Para seleccionar las unidades de análisis se tomó el criterio de factibilidad para el acceso a la información. Teniendo en cuenta que, como se podrá constatar en el siguiente apartado, una de las técnicas de recolección fue la observación participante, se constituyeron en unidades de análisis aquellos que participaron activamente de los espacios de tutoría durante el tiempo en que se llevó a cabo trabajo el campo. De la totalidad de participantes se escogió a quiénes entrevistar, este proceso se describe en el apartado siguiente.

Así pues, las unidades de análisis fueron estudiantes indígenas que cursaban sus carreras de grado en las diferentes Facultades de la Universidad Nacional de Salta y que forman parte del CEUPO. Es decir, no se trató de ningún pueblo en particular, sino que participaron del estudio jóvenes pertenecientes a diversas comunidades indígenas de la provincia de Salta.

La cantidad de personas participantes del estudio es difícil de precisar, ya que la no obligatoriedad de la participación en las actividades del ProTconPO y CEUPO genera que no exista un registro de sus integrantes, así como el hecho de que participen diferentes estudiantes en los encuentros. De modo general y sin precisión numérica, podemos decir que participaron alrededor de 50 jóvenes, aunque en la mayoría de las actividades el número no superaba los 20 . 
Para el trabajo de campo, se estableció un protocolo de consentimiento informado basado en la Ley 25.326/00 de Protección de Datos Personales. El consentimiento informado se consiguió por medio de la coordinadora del Proyecto, quien nos contactó con los y las integrantes, lo cual hizo posible obtener la autorización para realizar el trabajo de campo.

\subsection{Técnicas de recolección}

Para la elaboración de este artículo se retomó información obtenida de entrevistas en profundidad y observaciones participantes. El período cubierto por la investigación abarcó desde el año 2016 hasta el año 2019.

Las observaciones se desarrollaron durante el período comprendido entre la segunda mitad del año 2016 y la primera mitad del año 2018, solo en aquellas actividades para las que se recibió invitación por parte de integrantes del CEUPO o la coordinadora. Se evitó asistir a aquellas a las que la investigadora no fuera invitada expresamente, dado que quienes participan estaban debidamente informados del proceso de investigación y, quizá, no deseaban que dichas actividades formaran parte de este. El rol ocupado por la investigadora fue siempre de participante, al realizar las mismas acciones y dinámicas que los y las estudiantes, y como audiencia en los casos en que se trataba de charlas o conferencias. A partir de esta técnica, se recupera, desde nuestra propia perspectiva, lo que sucede en la práctica misma y los sentidos que se le otorgan a esta.

Estas observaciones fueron registradas mediante notas de campo y, en algunos casos, mediante grabaciones de voz, dependiendo de la dinámica de los encuentros, todas se realizaron con la debida autorización. Además, se evitó el registro en fotos, al considerar que el hecho de intervenir de esta manera podría perturbar las dinámicas de los espacios.

En cuanto a las entrevistas realizadas a estudiantes, estuvieron orientadas a la reconstrucción de las trayectorias socio-escolares a partir de narrativas biográficas. Para realizar esta reconstrucción se pone el foco en las intersecciones entre biografía y educación, que permiten reconocer la importancia que tienen las instituciones escolares en la (re)elaboración de los proyectos de vida. Esta decisión asume que, en educación, "la investigación narrativa y autobiográfica produce conocimientos sobre los sujetos en formación, sus relaciones con los territorios y tiempos del aprendizaje y sus modos de ser, hacer y biografiar resistencias y pertenencias" (Delory-Momberger, 2009, p. 7).

En correlación con la lógica de la investigación, se realizó una selección intencional de las personas a entrevistar, en tal sentido, fueron escogidas por su capacidad para generar 
información relevante y porque reunían algún criterio que, a nuestro juicio, era importante para los fines del estudio. En las investigaciones cualitativas, la selección de las personas a entrevistar está vinculada más a la significatividad que a la cantidad, ya que cada informante presenta particularidades a partir de las cuales se realiza el análisis, por lo que las muestras tienden a ser intensivas: se entrevistan pocos sujetos, pero en mayor profundidad (Yuni y Urbano, 2016).

Con base en lo planteado, se seleccionaron cinco personas para entrevistar, para lo cual se tomó como criterio que presentaran situaciones diferentes respecto a las tutorías. Con el fin de preservar sus identidades y resguardar su confidencialidad, se consignó un nombre de pila inventado para cada una de las personas entrevistadas:

- La autora del proyecto y coordinadora de los espacios de tutorías.

- Dos tutoras: Sara, perteneciente a una comunidad indígena, que aún no finalizó la carrera y que ha perdido contacto con las tutorías; y Nilda, extutora no-indígena, que se graduó y aún colabora con las tutorías.

- Dos participantes de las tutorías: uno indígena y una no-indígena, que participan en la mayor parte de las actividades propuestas desde el espacio de tutorías, es menester recordar aquí que las tutorías con pueblos originarios son de participación voluntaria.

En el desarrollo de las entrevistas realizadas entre julio de 2017 y febrero del 2019, se focalizó en las siguientes dimensiones, delimitadas con base en los objetivos de la investigación y al análisis de las observaciones participantes:

1. Reconstrucción autobiográfica, centrada principalmente en experiencias en los niveles previos de educación (inicial, primario y secundario).

2. Representaciones acerca de estudiar en la Universidad.

3. Elección de la carrera.

4. Percepciones y expectativas respecto al ProTconPO y el CEUPO.

5. Experiencia en el ProTconPo y el CEUPO.

Estos fueron los grandes ejes en torno a los cuales se desarrollaron las entrevistas.

\subsection{Procesamiento de análisis}

En concordancia con la lógica cualitativa de investigación no se considera el análisis como el momento culminante del estudio, sino como una actividad constante en el desarrollo de la investigación. Los datos obtenidos en las observaciones participantes se analizaron en 
un proceso continuo, que se solapó, incluso, con las mismas observaciones, ya que recolectar muchos datos sin reflexionar sobre ellos puede producir una acumulación de material sin sentido (Corbetta, 2007). Además, la reflexión y análisis constante permitieron orientar observaciones y definir cuestiones relacionadas con las entrevistas, como las personas a entrevistar y los ejes a abordar.

Siguiendo esta lógica se realizó un análisis descriptivo y narrativo, a partir del cual se organizó la información con base en categorías emergentes. Estas sirvieron para la elaboración de los instrumentos de entrevista y luego se analizaron, también, en relación con los datos obtenidos de estas últimas mediante triangulación de técnicas.

En cuanto a las entrevistas en profundidad, estas fueron registradas mediante grabaciones de voz en soporte digital por lo que, en primer lugar, se las transcribió textualmente. Este proceso formó parte del análisis, ya que permitió identificar algunas categorías emergentes. Seguidamente, se procedió a la categorización con empleo del software Atlas.ti versión 8.

\section{Resultados}

Como se anticipó, en este apartado se abordarán cada uno de los ejes identificados en las estrategias de retención y permanencia que se despliegan en la UNSa. Con fines organizativos, se desarrolla cada eje por separado, pero es menester aclarar que se encuentran fuertemente relacionados entre ellos. Por tal motivo, en el desarrollo, se hace referencia a los cruces que ocurren entre estos ejes en las estrategias de permanencia y retención.

\subsection{Aspectos formativos como estrategia de retención.}

El ProTconPO prevé el acompañamiento psicosocial y académico de estudiantes indígenas que deciden participar. Para ello, se realizan actividades que atienden al desarraigo, a problemáticas que este grupo de estudiantes reconocen de interés y a las dificultades que puedan tener en sus carreras y que, además, se relacionen específicamente con su identidad indígena. Por ejemplo, problemas con los textos por el idioma. Así, el apoyo en cuestiones atinentes a dificultades que son compartidas con el estudiantado en general se considera dentro de las funciones de los Servicios de Orientación y Tutoría que ofrece cada Facultad:

nosotros nos hemos propuesto que las cuestiones académicas sean resueltas por los otros tutores, porque tampoco nos parece que tenga que ser una tutoría así onda gueto. 
Me refiero al acompañamiento en las materias, a eso me estoy refiriendo puntualmente, que no sea esta cuestión del gueto de que por ejemplo si me cuesta la bioquímica, sólo es un espacio de bioquímica para los chicos de pueblos originarios, no, si te cuesta la bioquímica tenemos un espacio donde compartimos con los otros (Coordinadora del ProTconPO, entrevista, 27 de julio, 2017).

En la cita, la coordinadora indica que no se atienden cuestiones académicas "generales". Justifica esta decisión haciendo explícita la intención de no funcionar de manera aislada del resto de las estrategias de retención que existen en la universidad, orientadas al estudiantado en general. La construcción de sendas paralelas para el abordaje de la inclusión de estudiantes indígenas se considera una actitud segregacionista que refuerza la diferencia y la exclusión (Hanne, 2018). Ahora bien, en lo prescripto, no se encuentra referencia específica a estudiantes indígenas en otros documentos institucionales, referentes a políticas institucionales inclusivas dirigidas al estudiantado en general. Lo anterior conduce a cuestionar si en los espacios dispuestos para favorecer la retención se discute acerca de la diversidad cultural, así como si intentan o logran atenderla y de qué manera.

Es evidente que, sobre aspectos específicos de algunas asignaturas, ni tutores ni tutoras, ni coordinadora, ni integrantes del CEUPO tienen la formación necesaria para dar respuesta a las dificultades. Sería una exigencia absurda pretender un conocimiento sobre todos los contenidos de todas las materias que componen cada plan de estudios de las carreras de una Facultad. No obstante, sí se considera necesario que la universidad comience a contemplar la diversidad cultural en todas las políticas orientadas a la inclusión.

Pese a no ocuparse de los asuntos curriculares generales, el ProTconPO es un espacio formativo, paralelo y -a veces- complementario a la formación profesional que cada estudiante recibe en su carrera. Los aspectos formativos se presentan de diferentes formas. Una de ellas es el aprendizaje sobre otros pueblos indígenas. Al respecto, Sara plantea:

uno siempre está respetando todas, todas las creencias. Por ejemplo, nosotros no practicamos lo que es la pachamama, es la primera vez que escuché cuando llegué acá a la Universidad qué era la pachamama, que bueno que hay que darle ¿de comer? Para mí era algo que no tenía sentido, pero bueno, es la cultura del otro y hay que respetarlo, hay que acompañar en ese proceso de querer transmitir a la sociedad sobre la importancia de respetar a la "madre tierra" como dicen ellos (Sara, entrevista, 5 de marzo, 2018). 
Sara nos cuenta cómo en la universidad, además de aprender sobre la cultura occidental, aprendió sobre la cultura Kolla, respecto -por ejemplo- al ritual de la Pachamama ${ }^{4}$.

Otra manera en que se presentan los aspectos formativos es la posibilidad de instruirse como tutores. Resulta pertinente referir este aspecto como elemento orientado a la retención. Al respecto, Nilda comenta el impacto de su paso por las tutorías en su posterior desempeño como docente:

[...] esta tutoría ha cambiado incluso mi camino de formación docente $y$, siendo tutora luego [...] ya me recibí, y voy consiguiendo otros trabajos y todo esto, pero al fin y al cabo termino volviendo, por así decirlo, nunca me termino yendo de la universidad por este mismo vínculo con los chicos, con el espacio, con el servicio, con la tutoría (Nilda, entrevista, 31 de agosto, 2017).

Este testimonio pone de manifiesto de qué manera la experiencia como tutora influyó en posteriores decisiones profesionales de Nilda, ya que el vínculo con estudiantes indígenas profundizó sus deseos de desempeñarse como profesora, aunado a ello orientó ese trabajo docente hacia ciertas áreas: el ingreso y la educación intercultural. En este caso, la tutoría favoreció la retención y orientó la inserción laboral de una extutora, una función no contemplada en sus bases, pero importante en el contexto de incertidumbre respecto a las trayectorias laborales de los egresados (Rodríguez y Ossola, 2019).

En relación con esto último, es pertinente mencionar que un aspecto identificado como debilidad o deuda del ProTconPo y de la universidad en general es la imposibilidad de generar convenios que garanticen $\mathrm{o}$, al menos faciliten, el ingreso laboral de sus egresados y egresadas indígenas en ámbitos de incumbencia en sus propias comunidades o en alguna otra comunidad indígena.

Por ejemplo, a nivel salud o a nivel educación, que me parece que son como las dos áreas más sensibles o en las que uno podría hacer algo más para incidir favorablemente, nosotros no tenemos ni siquiera un convenio [...] Decir, bueno, si la Facultad puede dar cuenta de quince egresados que pertenecen a pueblos originarios en enfermería, bueno perfecto ¿no tienen prioridad para un nombramiento? ¿Que vuelvan a sus comunidades? [...] Porque convengamos que, en el área salud una de las mayores

\footnotetext{
4 Mediante el ritual de la Pachamama, el pueblo kolla homenajea a la "madre tierra" ofreciéndole productos valorados en estas comunidades como las hojas de coca, diferentes alimentos, cigarrillos, hiervas, diversas bebidas y papel picado simbolizando alegría.
} 
dificultades que tenemos es la inaccesibilidad al sistema por discriminación [...] no es algo tan complejo, es muy sencillo y tampoco lo podemos lograr. [...] Vos te das cuenta cómo los docentes van [a las escuelas de las comunidades] los dos últimos años para jubilarse [...] ¿Me vas a decir que ellos [los graduados indígenas] no deberían tener prioridad para acceder a algunos de esos puestos? Ponele que no haya en las escuelas de su comunidad, pero en alguna de las comunidades. Me parece que, en los órganos de decisión de los gobiernos, no pueden dimensionar lo positivo que sería contar con gente formada, del propio lugar, porque seguramente las cosas serían diferentes (Coordinadora del ProTconPO, entrevista, 27 de julio, 2017).

En este pasaje de la entrevista, la coordinadora explica una deuda de la universidad y el gobierno con la formación profesional de los jóvenes de pueblos originarios en relación con su futura inserción laboral. Además, hace referencia a que saldar esa deuda no es difícil, al menos en lo que respecta a egresados de las áreas de salud y educación, solo depende de una decisión política: priorizar a profesionales indígenas en aquellas instituciones que se encuentran en sus comunidades, o cercanas.

Interesa también sobre lo planteado por la coordinadora, el aporte que realiza a la discusión sobre el retorno a las comunidades. El hecho de no regresar a las comunidades una vez graduados no se relaciona con un abandono o falta de compromiso con su propio origen, en algunas ocasiones se debe a sentir que pueden contribuir más desde otros lugares. En otros casos no pueden volver porque no consiguen el lugar donde desempeñar su profesión. Al respecto, Santana Colin (2018) sostiene que se puede estudiar cualquier carrera y ponerla al servicio del pueblo, aunque para ello se deban buscar otros espacios donde desarrollar la militancia indígena, que no sea necesariamente desde el ámbito comunitario, sino muchas veces desde los contextos urbanos.

En cuanto al eje de los aspectos formativos, en la cita referida en páginas anteriores, Nilda también señala que las tutorías conforman un espacio pedagógico, un "sitio de aprendizaje" al que siempre vuelve, dando cuenta de que el apoyo social y la contención no son unidireccionales, sino que operan en múltiples direcciones. Como espacio formativo se vislumbra que las tutorías generan prácticas que luego resultan motivadoras para insertarse en otros ámbitos de la universidad, como la docencia:

[...] ya muchos [estudiantes del CEUPO] ya son tutores, ya muchos son auxiliares adscriptos, y que vos ves que ese rol va acompañado de otras cosas también, que las 
tutorías, tal vez han proporcionado, este otro espacio, de ver por el otro... eh... vos decís "bueno, creo que las expectativas o ciertos objetivos se cumplieron" (Nilda, entrevista, 31 de agosto, 2017).

Ello muestra otra arista que no forma parte de los objetivos iniciales del proyecto, que es el contacto con ciertas formas de enseñanza y aprendizaje, y con contenidos que resultan formativos para ejercer la docencia con un estilo que promueve la empatía (Rodríguez y Ossola, 2019). Esta formación, entonces, no se reduce a quienes se desempeñan como tutoras y tutores, sino que se extiende a todas las personas que conforman el ProTconPO. En este punto, es importante mencionar que la posibilidad de desempeñar este rol también actúa favoreciendo la retención de estudiantes, ya que deben cumplir los requisitos para obtener la Beca de Formación ${ }^{5}$.

Respecto a esto último, es pertinente mencionar que desde el CEUPO y el ProTconPO se intenta que los cargos de tutoras y tutores roten entre sus integrantes. Es decir, que al momento en que sea necesaria una nueva convocatoria para concursar alguno de los cargos haya integrantes del CEUPO para postularse. Esta es una forma de atender una de las cuestiones que reconocen como debilidad del ProTconPO:

Este hecho del cambio de tutores, o sea, si son treinta meses, son treinta meses, pero en esos treinta meses hay una gran construcción del vínculo, del tutor con el estudiante, $y$ ese estudiante tal vez le costó doce meses o un año y medio acercarse al tutor $y$ cuando lo ha logrado este tutor se está yendo. ¿Entendés? Entonces es como que eso también impide... no, no impide, porque... digamos, también este estudiante se ha acercado de alguna manera y termina acercándose, pero como que pone como obstáculos podríamos decir a que se terminen de construir ciertos vínculos con algunos chicos (Nilda, entrevista, 31 de agosto, 2017).

En esta cita, Nilda reconoce el cambio de la persona tutora como un aspecto que puede ocasionar dificultades para las relaciones interpersonales. Los vínculos afectivos identificados como uno de los ejes de las estrategias tanto de retención como de permanencia, se construyen, y los cambios pueden resultar perjudiciales para sostenerlos, sobre todo si el cargo lo obtiene alguien que no participaba previamente de las actividades del CEUPO.

\footnotetext{
${ }^{5}$ Las becas de formación son una figura de becas para que estudiantes avanzados realicen trabajos en diferentes áreas de la Universidad, son pagas y se accede a las mismas por concurso. Para poder concursar y mantener la beca es necesario cumplir con ciertos requisitos académicos como porcentaje de asignaturas aprobadas.
} 
Entonces, según el modo en que ocurra, el cambio de personas tutoras puede significar la pérdida de un referente afectivo importante, perjudicial para la retención, o una posibilidad de horizontalidad. En efecto, si los reemplazos se dan dentro del mismo grupo que viene desarrollando los vínculos, el obstáculo puede sortearse con cierta facilidad. Más aún, cuando extutores continúan participando de estos espacios. Es decir, que quien construyó lazos continúa participando, pero sin la responsabilidad que le otorgaba el cargo. Esta rotación de roles que se posibilita por tratarse de tutorías de pares resulta favorecedora de relaciones horizontales que permiten cierta reciprocidad.

Retomando el eje de los aspectos formativos, resulta pertinente hacer referencia a los proyectos de extensión que se realizan desde el ProTconPO. José los valora en este sentido: "el CEUPO me ha permitido estar en proyectos de extensión y con comunidades y otros espacios más que se trabaja con los chicos, entonces ha sido digamos parte de mi formación" (Entrevista José, participante del ProTconPO). Además, estos proyectos posibilitan que el estudiantado del CEUPO realice aportes a sus comunidades, a la vez que les permiten conocer las comunidades de sus compañeras y compañeros. En este aspecto, se encuentra un cruce entre dos de los ejes identificados: los aspectos formativos y los lazos afectivos.

Finalmente, los talleres se constituyen como espacios de formación sobre identidad indígena, derechos indígenas y otras cuestiones de interés para la población del CEUPO que es la que organiza las actividades. Al respecto, Sara señala:

también creo que [trabajar con tutores indígenas de otras facultades] me ayudó a que nos podamos formar, también y hacer cosas con los chicos, sobre todo los talleres más de identidad ¿no? Que es importante trabajar sobre eso” (Sara, entrevista, 5 de marzo, 2018).

En su discurso, Sara alude a dos cuestiones importantes. Por un lado, a que también el trabajo en equipo con estudiantes de las diferentes facultades es un aspecto que contribuye a la formación de los tutores. Por otro, que resulta central en este eje lo referido a la identidad. En relación con esto último, expresa, en otro momento de la entrevista:

"Creo que estos espacios nos permiten seguir manteniendo la cultura, porque creo que eso es importante: uno viene de una comunidad para formarse, pero no para olvidarse de la cultura, porque ¿qué sentido tiene venir a formarme y después me formo en todo lo que me enseñaron en la Universidad y me olvidé todo lo que aprendí en la comunidad?" (Sara, entrevista, 5 de marzo, 2018). 
Así, se combina a partir de estos espacios, la formación occidental, con la formación indígena. Este es para Sara el valor central de las tutorías, la contribución a no olvidarse de la propia cultura. Nuevamente se halla un cruce entre dos de los ejes, en este caso los aspectos formativos y la reivindicación de la identidad indígena. Sobre esto, Santana Colin (2018) plantea que la profesionalización de los indígenas contribuye a lograr una politización más sólida, apareciendo distintas formas de militancia.

El mencionado cruce pone en evidencia una cuestión relevante: el igual valor otorgado a los saberes indígenas y los saberes de la academia, paridad que posibilita un genuino diálogo de saberes. Si bien ésta no es una característica que pueda atribuírsele a la UNSa, la experiencia en estos espacios constituye un valioso avance hacia la inclusión en términos interculturales.

\subsection{La reivindicación de la identidad indígena como estrategia de permanencia}

En la definición formal que elaboraron quienes conforman el CEUPO, para presentar en sus actividades, se pone de manifiesto, como objetivo propio, el reconocimiento y respeto de la diversidad cultural en la UNSa. Este grupo de estudiantes se autodefine expresando:

Somos un grupo de estudiantes universitarios que lucha por el reconocimiento y el respeto a la diversidad cultural en nuestra Universidad. En este grupo participamos en forma voluntaria estudiantes de las diferentes facultades, compartiendo saberes, conocimientos y experiencias de nuestras culturas y la vida en la Universidad. Somos una comunidad que tiene voz, somos eco de nuestras culturas ancestrales, con identidad, con historia; somos una comunidad que se abre caminos en esta UNIVERSIDAD (Comunidad de Estudiantes Universitarios de Pueblos Originarios, s.f., Inicio)

En esta definición deja en evidencia como eje de las estrategias de permanencia, en este grupo de estudiantes indígenas, la reivindicación y visibilización de su identidad indígena.

Del análisis de la información provista por las entrevistas realizadas surge como aspecto común la mención de la Feria Intercultural como la actividad central del ProTconPO y el CEUPO. Este evento consiste en una jornada, que dura todo un día, en el que se combinan talleres, conferencias sobre diferentes temáticas -a cargo de algunos integrantes del CEUPO y también de referentes comunitarios, como aquellos que se ocupan de la medicina comunitaria o los caciques-, además algunos llevan sus artesanías y productos de sus respectivas comunidades para dar a conocer e incluso venderlos. 
Es muy similar a las ferias características del pueblo kolla. Se trata de espacios de intercambio, en los que se habilitan encuentros y celebraciones que sirven para fortalecer vínculos, intercambiar y difundir conocimientos y saberes tradicionales e innovadores de base tradicional de cada pueblo, contribuyendo al fortalecimiento de la identidad indígena.

Respecto a este punto, el homenaje a la Pachamama que se realiza todos los años, en más de una ocasión, es también una forma de visibilización de la identidad indígena. Además, se celebra el solsticio de invierno como año nuevo andino. Si bien estas actividades son propias de algunos pueblos, permiten la visibilización de todos los representados en el CEUPO. También se realizan actividades por el día de la mujer indígena y se comparte el lugar de la mujer en cada pueblo y comunidad, ya que también existen diferencias entre comunidades pertenecientes al mismo pueblo.

En la organización de la feria intercultural participa cada integrante del CEUPO que así lo desea, hay lugar para compartir sobre cada cultura, y resulta la actividad más convocante para el estudiantado del CEUPO y para la comunidad universitaria en general. Al respecto, Nilda comenta:

la Feria Intercultural, que se trata de mantener año tras año, que es un lugar donde, si bien algunos chicos no participan durante todo el año, pero es como que... ese día están, como que ese día tenemos la gran cantidad de chicos participando, por ejemplo, en el diseño, en la organización de la Feria Intercultural. Como que es su momento en el año. (Nilda, entrevista, 31 de agosto, 2017)

Como se anticipó en un apartado anterior, la participación en los espacios del CEUPO y del ProTconPO no es regular, al ser voluntaria, a cada actividad concurren personas diferentes, aunque algunas personas participan más y otras menos. Sin embargo, como plantea Nilda, en la feria es donde todas deciden estar. Éste no es un dato anecdótico, ya que es la actividad del ProTconPO donde más se exterioriza y comparte información sobre cada cultura y la que más alcance posee por la gran asistencia de la comunidad universitaria.

De este modo, se refuerza la reivindicación de la identidad indígena, como estrategia de permanencia. En relación con este tipo de estrategia, Soto et al. (2020) plantean que la búsqueda de estudiantes de pueblos originarios por hacerse visibles como actores activos en la universidad es una apuesta ético-política importante en tanto surge como iniciativa propia. Así, la interculturalidad se da a través de la participación indígena y en ese proceso la iniciativa propia de estudiantes indígenas cobra una importancia central. 
Otra cuestión importante sobre este evento es que sirve para que se acerquen estudiantes que no participan del ProTconPO. Sara no participaba antes de ser tutora, decidió sumarse al concursar y ganar el cargo, pero previo a ello, ya se acercaba a las ferias interculturales: Sí sabía del CEUPO, iba muy poco, sólo en las ferias a participar, a ver. Pero después participé más activamente cuando fui tutora. (Sara, entrevista, 5 de marzo, 2018). La feria adquiere, entonces, otro valor: existen estudiantes indígenas que se acercan al CEUPO por ella.

Es importante mencionar que la reivindicación de la identidad indígena como estrategia de permanencia no se relaciona sólo con la divulgación de los saberes y costumbres ancestrales en la comunidad universitaria, sino que tiene que ver además con un trabajo de diálogo interno. De tal modo, este eje contribuye a abordar el desarraigo: "aun estando en la ciudad, seguimos compartiendo y conservando nuestras tradiciones" plantea un estudiante en la actividad de bienvenida a ingresantes del año 2018. Se resume en esas palabras el desarraigo -estar en la ciudad- y la forma de afrontarlo -compartir y conservar las tradiciones, que se llama aquí estrategia de permanencia.

Respecto a la importancia del diálogo interno, Marta sostiene en su entrevista que, si bien son importantes las actividades pensadas para compartir sus costumbres con toda la comunidad universitaria, sería importante realizar más acciones orientadas internamente:

Creo que a la larga se tendrian que planificar más actividades que hagan que a los chicos les interese y se sientan como yo me sentí cuando ingresé, cuando yo ingresé al CEUPO se hacían muchas actividades, entonces tenías más oportunidades de conocer el grupo, de conocer los tutores, conocer a las otras facultades y los otros chicos. Pero estos últimos tiempos, yo asumí que hay menos actividades, antes se organizaban hasta partidos de fútbol, comidas, entonces compartíamos más (Marta, entrevista, 12 de febrero, 2018).

Así, otra forma de atender el desarraigo, a partir de la reivindicación de la identidad indígena, consiste en poder dialogar y sentirse comprendido por otras personas que están viviendo situaciones similares. Cuando Marta refiere a lo que sintió cuando ingresó, alude a otro momento de la entrevista en el que relató:

sentía que yo podía contar quién era, podía, qué era lo que hacía y de dónde venía y me gustaba participar porque yo sentía que los chicos con los que estaban se sentían igual, que podíamos compartir muchas cosas, que nos apreciamos mucho y que era un 
lugar que nos dejaban hablar, nos dejaban contar cosas y que todos disfrutaban contar quienes eran. (Marta, entrevista, 12 de febrero, 2018).

En este pasaje del relato de Marta, se puede reconocer un cruce entre el eje de la identidad indígena y el de los aspectos afectivos, en tanto se desarrollan estos lazos a partir de cierta empatía producida al haber vivido experiencias similares por sus identidades indígenas. Esto genera una confianza para compartirlas y -a la vez-permite ir construyendo redes afectivas, el CEUPO y el ProTconPO son los espacios donde estudiantes indígenas se sienten seguros. Por lo tanto, compartir sus costumbres ancestrales con toda la comunidad universitaria resulta importante, pero encontrar lugares íntimos para poner en común sus experiencias como jóvenes indígenas, posee también un valor significativo para su permanencia. Se encuentra aquí una doble dimensión en la reivindicación de la identidad indígena: una referente a la comunidad y otra a los sujetos. Esta última, se relaciona directamente con la construcción de lazos afectivos.

\subsection{Los lazos afectivos como estrategias de retención y permanencia}

Este tercer eje se encuentra entrelazado con casi todas las estrategias de retención y permanencia. El análisis realizado permite identificar a los aspectos formativos como direccionados a la retención y la reivindicación de la identidad indígena como inherente a estrategias de permanencia. En la división que se realizó a fines analíticos, lo formativo sería propio del ProTconPO, mientras que la necesidad de compartir la identidad indígena, inherente al CEUPO.

Los lazos afectivos, se evidencian en ambos sentidos -retención y permanencia-. Son estos vínculos los que llevan al reconocimiento de estos espacios como "una familia". La idea de relacionar el CEUPO con comunidad o familia, se reitera en conversaciones informales, entrevistas y encuentros observados. Respecto a lo afectivo como estrategia de retención, la coordinadora comenta: son muchas las cosas que uno hace en lo cotidiano que probablemente no aparecen, pero si son los que anclan o van tejiendo esa red de contención entre todos (Coordinadora del ProTconPO, entrevista, 27 de julio, 2017) Así, por ejemplo, si se enferma alguno de los "ceupitos" -modo en que llaman a las hijas e hijos de quienes integran el CEUPOse intenta organizar el cuidado de las otras niñas y niños, el trasporte para atención sanitaria, entre otros, como cuestión solidaria y afectiva. 
También estos lazos o "tejidos" se fortalecen con las ayudas a los lugares de origen. En el año 2018, por ejemplo, la crecida del río Pilcomayo afectó fuertemente a algunas comunidades de las que provienen estudiantes -particularmente Wichí- y desde el CEUPO se organizó una colecta de donaciones y viajes para entregarlas. Marta, narró esta experiencia en la entrevista e hizo referencia a lo importante que fue para ella y sus compañeros:

Fue muy conmovedor, porque siempre hablábamos con los chicos ahí y nos contaban como eran sus pagos, [...] pero nunca habíamos tenido la oportunidad de ir y esa vez fuimos y no conocimos como nos contaban, por lo que había pasado. Siento que como grupo nos conocimos también, supimos cómo trabajar, vimos el interés que teníamos con nuestros compañeros, amigos, que estaban, que habían sido afectados (Marta, entrevista, 12 de febrero, 2018).

Así como Sara, siendo wichí, aprendió sobre la cultura kolla, Marta había escuchado sobre "los pagos" de sus compañeros wichí, su cultura, sus costumbres y modos de vida. Fue una catástrofe natural la que ocasionó que esta joven conozca estas comunidades. Pero ese infortunio permitió fortalecer lazos afectivos, a la vez que el tejido de contención que vienen construyendo desde el año 2010 les permitió organizarse de manera oportuna para ayudar a las comunidades afectadas.

Al analizar el eje de aspectos formativos, se hizo referencia a la intención de que el ProTconPO y el CEUPO no funcionen como sendas paralelas que tiendan a aislar a estudiantes indígenas. En cuanto a este "tejido de contención" al que se alude con los lazos afectivos, es preciso mencionar que no es necesario ser indígena para formar parte de estos espacios y que la participación de estudiantes no-indígenas no se produce sólo por concursar cargos de tutores. Si bien la conformación inicial fue en este sentido, la incorporación de José permitió a quienes integran el CEUPO notar que podían invitar a estudiantes no-indígenas a unirse. José narró en su entrevista cómo se enteró de la existencia de este grupo y decidió sumarse:

En el curso de ingreso, Sara andaba haciendo las encuestas [...] y como yo ya venía con un conocimiento previo de las comunidades que estaban ahí cerca de mi casa, porque yo tenía amigos, tengo amigos que son wichí, yo vengo con algo del idioma, entonces dije me parece buenísimo que pueda ayudar, aportar. [...] bueno, yo creo que puse todos mis datos y dije que venía de un lugar donde había comunidades, que conocía, conocimiento de la cultura y el idioma, que si necesitaban ayuda yo estaba con 
ellos. Después me acerqué y me acuerdo que la salude en el idioma, la Sara se rió porque era como... o sea ella después me dice que era la primera vez que sentía que 'uy encontré alguien de pueblo originario' y bueno nada yo le entregué digamos y esperaba su mail o mensaje y no me llegaba, así que yo la empecé a buscar, [...] yo la busqué a ella hasta que, bueno, pudimos encontrarnos y ahí empezar a charlar, le conté toda mi experiencia, de dónde venía, ahí como que también empezó una buena relación de amistad con ella y después con su hermana y con todos (José, entrevista, 19 de febrero, 2019).

Con el relato de José, es posible reconocer cómo la inclusión puede darse en varios sentidos y existe una posibilidad real de pensarla en términos interculturales. Además, permitió un cambio en la mirada de quienes integran el CEUPO que, en los últimos años, cuando recorren las aulas del curso de ingreso, recuerdan que quienes no pertenecen a pueblos originarios, de todos modos, pueden sumarse, si lo desean.

Con esto, se evidencia que las experiencias de interculturalidad, de disputa al MCMC, no representan una exclusión a lo no indígena. Es decir, las y los estudiantes indígenas no conservan estos espacios como trincheras de resistencia que dejan por fuera a quienes no se reconocen como tales, no reproducen -a la inversa- la exclusión y marginalidad a la que el MCMC los ha relegado, individualmente, como comunidades y como pueblos. Por el contrario, demuestran la apertura al diálogo que caracteriza la interculturalidad.

\subsection{Expectativas y perspectivas a futuro sobre el ProTconPO y el CEUPO}

Una forma pertinente de repensar las políticas educativas que pretenden ser inclusivas es escuchando a quienes se intenta incluir. Se ha planteado, en este trabajo, la inclusión, en términos interculturales, para la cual es necesario salir de la mirada lineal y unidireccional, es posible identificar en el CEUPO un lugar donde se encuentran experiencias en este sentido y que pueden constituirse en cimientos desde los cuales ir recorriendo caminos hacia nuevos horizontes. Esto puede permitir corroer los cimientos del MCMC y contribuir en el proceso de una universidad que atienda de manera intercultural a la diversidad que la caracteriza.

Ahora bien, quienes construyeron y dieron forma a este espacio expresan sus expectativas y perspectivas a futuro sobre el CEUPO y el ProTconPO. Estas abarcan aspectos variados y también se encuentran atravesadas por los ejes de la formación, la reivindicación de la identidad indígena y los lazos afectivos. Sara, por ejemplo, sostiene: 
Espero que siga creciendo el CEUPO, que haya más tutores en todas las facultades, porque no hay, en Ingeniería no hay, así que estaría que haya no un tutor por Facultad, sino por lo menos dos para que puedan trabajar más, con más tranquilidad con los chicos, acompañarlos más. [...] Ojalá que siga creciendo el CEUPO y que puedan ser... no sé, que los chicos puedan seguir creciendo y que se animen a plantear las cosas, y que también uno pueda respetar la opinión del otro. Eso me gustaría (Sara, entrevista, 5 de marzo, 2018).

Se evidencia cómo para ella el crecimiento del CEUPO se daría por dos cuestiones: la mayor cantidad de tutores y mayor participación de estudiantes indígenas, basada en el respeto. La primera refiere a la atención de dos aspectos importantes para la permanencia y retención, como lo son las cuestiones económicas -posibilitando a más integrantes cobrar por la beca de formación- y el acompañamiento académico y psicoafectivo -realizado por tutores. De este modo, las expectativas y perspectivas a futuro se relacionan con lo afectivo y con la reivindicación de la identidad indígena. Además, se encuentra teñida de una perspectiva intercultural en que todas y todos participen, con base en el respeto de opiniones diversas.

Por su parte, José plantea que existe un gran crecimiento del CEUPO expresado en hacerse visible como comunidad dentro de la universidad. Sostiene que cuando ingresó casi no se conocía este espacio y el trabajo de años permitió que se fuera instalando. Por ello, su perspectiva a futuro se relaciona con la continuidad de tal crecimiento:

Creo que lo importante es visibilizar más, para que los chicos mismos dentro de la universidad puedan también conocer, aquellos que no son de pueblos originarios puedan conocer que hay chicos de pueblos indígenas dentro de la universidad. Entonces el CEUPO creo que sirve para eso también, si bien se necesita un trabajo mucho más grande de años, yo creo que ya viene el CEUPO trabajando mucho acá en la universidad con otros chicos también y de a poco va creciendo y con el tiempo creo que ya se va a instalar y todo el que sea de la UNSa va a saber que hay estudiantes indígenas y que son del CEUPO. Pero también si no hay un compromiso desde arriba hasta abajo por ahí puede haber algunas dificultades, algunos problemas para que se visibilice más, para que la universidad pueda conocer. (José, entrevista, 19 de febrero, 2019). 
Se encuentran, en este caso, nuevamente expectativas de crecimiento, pero relacionadas a la visibilización, coherente con la reivindicación de la identidad indígena. Además, en la cita, el estudiante refiere la falta de compromiso de las autoridades universitarias, así como de otros actores universitarios. Se suma, entonces, como expectativa, el compromiso en los distintos niveles de gobierno universitario ("de arriba hasta abajo") con el ProTconPO, que tenga como consecuencia un crecimiento del espacio.

En relación con este compromiso por parte de las autoridades, la coordinadora hace hincapié en la importancia de recuperar un apoyo desde lo académico:

yo creo que es importantísima la presencia de la cuestión académica por todo lo que te dije antes: cómo vamos incorporando otras cosas, cómo problematizamos dentro de las cátedras, por lo menos de primer año, con algo hay que empezar, digamos. Eh... yo creo que esa cuestión es una debilidad importante. (Coordinadora del ProTconPO, entrevista, 27 de julio, 2017).

La coordinadora pone el foco en aquello que desde el ProTconPO se puede avanzar, como estrategia de retención, relacionado con lo que estaba prescripto en el Proyecto y no pudo concretarse por cuestiones de cambios en el gobierno universitario. Así, se encuentra presente en sus expectativas la intervención en la cuestión curricular, con fines interculturales. Aunque, en sus propias palabras "estamos muy lejos de ser una universidad intercultural". Sobre esto último, Sara sostiene:

creo que es de a poco, la universidad de a poco lo está... está incluyendo eso [la interculturalidad], pero bueno, eso va a tardar, de que toda la universidad sea algo que sea intercultural. Porque bueno, hay docentes que todavía no... les cuesta pensar en eso del otro, que es diferente (Sara, entrevista, 5 de marzo, 2018).

En este pasaje, la estudiante también esboza la expectativa de que, con el tiempo, la UNSa pueda ser intercultural, aunque deja claro que esto no sucederá en el corto plazo. La particularidad de su discurso es referir a la población docente como quienes se resisten a ese cambio. Así, se encuentran dos niveles desde donde pueden surgir las experiencias que permitan incluir en términos interculturales: las decisiones institucionales y las áulicas, claramente son esferas con influencia variable a las que se podría sumar al Estado Nacional, cuyo poder decisivo sería más influyente. Respecto a esto último es menester remarcar la necesidad de políticas nacionales que garanticen el ingreso, permanencia y egreso de indígenas, planteada por Artieda et al. (2017). 
Marta, por su parte, relaciona el crecimiento del CEUPO con la posibilidad de realizar más actividades que permitan fortalecer lazos entre pares:

Espero que a futuro el CEUPO pueda planificar más actividades que hagan que a los chicos les interese quedarse y participar, porque en las actividades es donde nos hacemos amigos. Para eso creo que deberíamos reforzar, quiero decir ser más, no sólo más tutores, sino ser más los que organizamos actividades. Pero con las obligaciones del estudio se complica a veces (Marta, entrevista, 12 de febrero, 2018).

Así, Marta plantea un crecimiento en términos de cantidad de actividades a desarrollar desde el CEUPO, lo cual se relaciona con la necesidad de aumentar tutores y participantes, aludida por Sara. Pero, además, Marta refiere a un aspecto central como lo son los tiempos universitarios. Cualquier actividad extra implica una gran organización para no perder oportunidades de aprobar materias, este también es un tema abordado en el CEUPO ya que la prioridad es graduarse, por lo que tratan de organizarse para poder llevar adelante las carreras y las actividades del CEUPO.

Finalmente, se considera relevante mencionar que, en muchos casos, las expectativas sobre estos espacios se cruzan con la autobiografía y las expectativas personales-familiares. Al respecto, resulta significativo que, en uno de los encuentros, una de las integrantes del CEUPO que ya se graduó, expresó su interés por fortalecer estos espacios para los futuros estudiantes indígenas, al hacer referencia específica a la expectativa de que su hijo estudie en la UNSa.

\section{Conclusiones}

En el caso estudiado, todas las estrategias de inclusión se desarrollan desde los espacios del CEUPO y el ProTconPO. El análisis realizado evidencia un tejido de contención, constituido por todas las estrategias de retención y permanencia, y por las relaciones entre ellas. Esto es así, por cuanto estos espacios no solo comprenden un apoyo académico, sino también, y principalmente, una instancia de construcción de lazos afectivos, esta se constituye en una dimensión central para la retención y permanencia de estudiantes indígenas en la UNSa.

Se sostiene, entonces, que el ProTconPO es la principal estrategia de retención, mientras que el CEUPO se constituye como la estrategia de permanencia más importante, y en ambos se va "enredando" el tejido mencionado. Cuando se habla de "enredar" se está 
aludiendo a que ese tejido no es planificado, sino que se construye en la práctica misma con base en las relaciones entre los sujetos, en las problemáticas que se presentan y en los aspectos que, en cada momento, resultan necesarios atender.

El análisis de las experiencias de estudiantes indígenas y de la forma en que se despliegan las estrategias de retención y permanencia de forma entrelazada nos permite reconocer al ProTconPO y al CEUPO como espacios interculturales. Así, se evidencia que quienes los conforman pertenecen a diversos pueblos indígenas, se identifican con culturas distintas e, incluso, encuentran diferencias dentro de un mismo pueblo, y en esa diversidad propician un diálogo intercultural. Es decir, relaciones basadas en la aceptación mutua y superadora, sin establecimiento de jerarquías y fortaleciendo la diversidad en la diversidad. Sin embargo, no existe una aparente proyección institucional de esta perspectiva intercultural, lo cual se evidencia en la ausencia de la temática en las normativas, planes de estudio, estatuto, entre otros.

Es posible, entonces, sostener que el ProTconPO representa un avance importante en la política de retención para el estudiantado indígena de la UNSa. No obstante, toda la responsabilidad al respecto recae sobre los propios estudiantes indígenas, tutores pares y su coordinadora, personas con clara afinidad por la temática.

Finalmente, las expectativas y perspectivas a futuro del ProTconPO y del CEUPO, que plantean sus integrantes, aluden al crecimiento. Entendido este en diversos sentidos: más tutores, más participación de estudiantes indígenas, más visibilización de los espacios y de la identidad indígena, mayor compromiso de las autoridades, modificaciones de los currículos, mayor respeto a la diversidad, entre otros. Ahora bien, no se encontraron indicios de un interés institucional por generar acciones orientadas a que estos espacios crezcan, en ninguno de los sentidos aludidos. Si la Universidad asume el compromiso de la inclusión de jóvenes indígenas, en términos interculturales, tendrá que estar dispuesta a transformarse a sí misma en muchos de los aspectos conservadores que aún persisten en ella y que significan obstáculos para ese proceso.

Un aspecto importante para tener en cuenta como limitación de esta investigación y posible arista para profundizar es la coyuntura de pandemia de covid-19 en la que se termina de cerrar el trabajo. Este contexto decantó en medidas preventivas, en el país y la provincia, que ocasionaron una situación particular respecto a la educación en general y la de nivel superior universitario en particular, signadas principalmente por una migración a la virtualidad, lo cual tiene un impacto particular en la población estudiantil indígena del CEUPO. Así pues, 
dos de los tres ejes de las estrategias de retención y permanencia identificados, podrían verse afectados y modificados por la distancia que ocasiona la no presencialidad de las actividades. Nos referimos a los lazos afectivos que se sostenían en la presencialidad y a la reivindicación de la identidad indígena que se expresaba, principalmente, en la realización de actividades en el predio universitario. Muy posiblemente las estrategias deban transformarse y adaptarse en el contexto de pandemia y pospandemia. El tercer eje, referido a los aspectos formativos, también se puede ver modificado por las dificultades de acceso a conectividad y dispositivos.

Es posible sostener que la coyuntura por covid-19 profundiza la desigualdad educativa de las universidades. Cabría preguntarse qué pasará en el contexto de postpandemia y, específicamente, cómo podría profundizar las dificultades para el acceso, la permanencia, la retención y el egreso de estudiantes indígenas en las universidades nacionales. Más aún cuando los debates respecto al retorno a las actividades académicas se encuentran actualmente orientados a la idea de una bimodalidad que combine el trabajo presencial con el virtual.

\section{Referencias}

Artieda, Teresa., Rosso, Laura., Luján, Adriana., y Zamora, Leko. (2017). Programa Pueblos Indígenas de la Universidad Nacional del Nordeste. Algunas reflexiones y propuestas en torno a la inclusión y la interculturalidad. En Daniel Mato (Comp.), Educación Superior y Pueblos Indígenas y Afrodescendientes en América Latina. Políticas y prácticas de democratización, interculturalización e inclusión (pp. 41-56). Buenos Aires: EDUNTREF.

Bonilla Castro, Elssy., y Rodríguez, Penélope. (1997). Más allá del dilema de los métodos. Bogotá: Ediciones Uniandes-Grupo Editorial Norma.

Buchbinder, Pablo. (2006). La Universidad: breve introducción a su evolución histórica. Universidad Nacional del Litoral. https://ingresopu.files.wordpress.com/2015/10/buchbinder evolucion-historica-2008.pdf

Carli, Sandra. (2012). El estudiante universitario: Hacia una historia del presente de la educación pública. Buenos Aires: Siglo XXI.

Comunidad de Estudiantes Universitarios de Pueblos Originarios. (s.f.). Inicio [Página de Facebook] Facebook. https://www.facebook.com/CEUPO-Comunidad-de-EstudiantesUniversitarios-de-Pueblos-Originarios-463746263836116/

Corbetta, Piergiorgio. (2007). Metodología y Técnicas de Investigación Social. Madrid: McGRAW-HILL. 
Coronado, Mónica., y Gómez Boulin, María José. (2015). Orientación, tutorías y acompañamiento. En Educación Superior. Análisis de las trayectorias estudiantiles. Los jóvenes ante sus encrucijadas. Buenos Aires: Noveduc.

Czarny, Gabriela., Ossola, Macarena., y Paladino, Mariana. (2018). Presentación al dossier Jóvenes indígenas y universidades en América Latina: sentidos de la escolaridad, diversidad de experiencias y retos de la profesionalización. Antropología Andina Muhunik-Jathasa, http://revistas.unap.edu.pe/antroa/index.php/ANTRO/article/view/320 $5(1)$.

Delory-Momberger, Cristina. (2009). Biografía y Educación: figuras del individuo-proyecto. Argentina: Editorial de la Facultad de Filosofía y Letras UBA.

Denzin, Norman., y Lincoln, Yvonna. (2005). The Sage Handbook of Qualitative Research. Londres: Sage.

Freire, Paulo. (1987). Pedagogía del oprimido (36a. ed.). México: Siglo XXI

González, Facundo (2020). Producción y circulación de sentidos en la configuración de las dimensiones supra e infra hábitat. Experiencias de producción de hábitat en la Puna y en el Chaco salteños a partir de proyectos de extensión con la comunidad Kolla de Hurcuro y el pueblo Wichí de El Cocal (Salta, 2017-2018) (Tesis de Doctorado). Universidad Nacional de Córdoba. Córdoba, Argentina.

Guaymás, Álvaro. (2018). Educación superior y pueblos indígenas y afrodescendientes en Argentina: logros, desafíos y recomendaciones. En Daniel Mato (coord.), Educación superior, diversidad cultural e interculturalidad en América Latina (pp. 37-62). Caracas: UNESCO - IESALC y Córdoba: Universidad Nacional de Córdoba.

Guber, Rosana. (2011). La etnografía: Método, campo y reflexibilidad. Buenos Aires: Siglo XXI.

Hanne, Valeria (2014). Politicas de acción afirmativa en Educación Superior: el caso de la UNCuyo. Mendoza: Zeta ediciones.

Hanne, Valeria. (2018). Estudiantes indígenas y Universidad: realidades y retos ante la diversidad cultural. Caso de la Universidad Nacional de Salta. Alteridad, 13(1), 14-29. doi: https://doi.org/10.17163/alt.v13n1.2018.01

Instituto Nacional de Estadísticas y Censos (INDEC). (2010). Censo Nacional de Población, Hogares y Viviendas 2010. República Argentina.

Lobato Fraile, Clemente., e Ilvento, María Celia. (2013). La Orientación y tutoría universitaria: una aproximación actual. Revista de Docencia Universitaria, 11(2), 17-25. doi: https://doi.org/10.4995/redu.2013.5564

Lujan, Adriana., y Torres, Jonatan. (2014). Jóvenes indígenas y educación superior. Experiencia en el acceso y permanencia en la Universidad. VIII Jornadas de Sociología de la Universidad Nacional de La Plata. http://jornadassociologia.fahce.unlp.edu.ar 
Luján, Adriana., Soto, Mirian., y Rosso, Laura. (2018). Experiencias de ingreso y permanencia de estudiantes indígenas en una universidad convencional del nordeste Argentino. Antropología Andina Muhunchik http://revistas.unap.edu.pe/antroa/index.php/ANTRO/article/view/322

Mato, Daniel. (2015). Educación Superior y Pueblos Indígenas en América Latina. Buenos Aires: EDUNTREF.

Novaro, Gabriela., y Hecht, Ana Carolina. (2017). Educación, diversidad y desigualdad en Argentina. Experiencias escolares de poblaciones indígenas y migrantes. Argumentos, 30(84), 57-76. https://www.redalyc.org/articulo.oa?id=59552650004

Ossola, María Macarena. (2013). Jóvenes wichí en la educación superior de Salta: interpelaciones escolares, étnicas y etarias (Tesis Doctoral). Universidad de Buenos Aires, Buenos Aires, Argentina.

Ossola, María Macarena. (2018). Educación superior y diversidad cultural. Análisis de las experiencias formativas de jóvenes indígenas en proyectos de extensión universitaria. Praxis Educativa, 22(3), 56-63. doi: https://doi.org/10.19137/praxiseducativa-2018$\underline{220306}$

Rodríguez, Nuria., y Sulca, Elisa. (2020). El acceso a la educación y la inclusión socioeducativa de estudiantes indígenas. Provincia de Salta-Argentina. TEXTURA - Revista de Educação e Letras, 22(51), 194-218. doi: https://doi.org/10.17648/textura-2358-0801$\underline{\mathrm{v} 22 \mathrm{n} 51-5683}$

Rodríguez, Nuria., y Ossola, Macarena. (2019). Tutoría universitaria y educación intercultural: debates y experiencias. Alteridad, 14(2), 172-183. doi: https://doi.org/10.17163/alt.v14n2.2019.02

Rosso, Laura. (2019). Universidades convencionales y participación indígena. Análisis de una experiencia en Chaco, Argentina. Tellus, 19(38). doi: https://doi.org/10.20435/tellus.v19i38.593

Rosso, Laura., Artieda, Teresa., y Luján, Adriana. (2016). Universidad y Pueblos Indígenas del Chaco. Análisis de una política de inclusión, participación e interculturalidad. En Daniel Mato (coord.), Educación Superior y Pueblos Indígenas en América Latina. Experiencias, interpelaciones y desafíos (pp. 371-390). Buenos Aires: EDUNTREF.

Santana Colin, Yasmani. (2018). Formación académica y militancia de los intelectuales indígenas mexicanos. Avá Revista de Antropología, 33, 79-102. https://www.redalyc.org/articulo.oa?id=169062373004

Soto, Mirian., Luján, Adriana., y Rosso, Laura. (2020). Nuevas lecturas a la permanencia de estudiantes indígenas en una universidad argentina. Movimento-Revista de educação, 7(13). doi: https://doi.org/10.22409/mov.v7i13.41246

Stake, Robert. (1994). Case Study. En Norman Denzin and Yvonna Lincoln (Eds.), Handbook of Qualitative Research. Londres: Sage. 
Stake, Robert. (1995). The Art of Case Study. Londres: Sage.

Tintaya Condorí, Porfidio. (2003). Utopías e Interculturalidad: Motivación en niños aymaras. La Paz: Instituto de Estudios Bolivianos.

Walsh, Catherine. (2010). Interculturalidad Crítica y Educación Intercultural. En Jorge Viaña, Luis Tapia y Catherine Walsh (Comps.), Construyendo Interculturalidad Crítica (pp. 7596). La Paz: Instituto Internacional de Integración del Convenio Andrés Bello.

Wigdorovitz de Camilloni, Alicia. (2008). El concepto de inclusión educativa: definición y redefiniciones. Políticas $\quad$ Educativas-Campinas, 1 2(1), https://seer.ufrgs.br/Poled/article/view/18347

Yuni, José., y Urbano, Claudio. (2016). Técnicas para investigar. Córdoba: Brujas. 
Revista indizada en

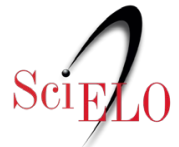

redalyc lationdex

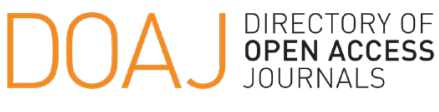

Distribuida en las bases de datos:
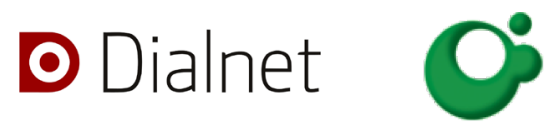
SHERPA/RøMEO

REDIB

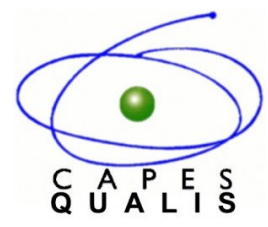

MIAR 